ISSN: 2162-3104 Print/ ISSN: 2166-3750 Online

Volume 6, Issue 3 (2016), pp. 798-816

(C) Journal of International Students

http://jistudents.org/

\title{
Advanced ESL Students' Prior EFL Education and Their Perceptions of Oral Corrective Feedback
}

\author{
Eun Jeong (Esther) Lee \\ Claflin University, South Carolina, USA
}

\begin{abstract}
The author in this study examines how advanced-level adult English as a Second Language (ESL) students' previous English as a Foreign Language (EFL) classroom experiences influence their perceptions of their teachers' oral corrective feedback (CF). It uses in-depth qualitative data to characterize the participants' prior English learning, and to determine how their experiences influence how they perceive CF in ESL classrooms. Understanding these patterns of perception will enhance ESL professionals' abilities to create effective and culturally sensitive ESL classrooms.
\end{abstract}

Keywords: International English education, English as a Foreign Language (EFL), oral corrective feedback, advanced-level ESL students

Several researchers (Kim, 2004; Rezaei \& Mozaffari, 2011; Russell, 2009; Sheen, 2010; Yang \& Lyster, 2010) have suggested that the effectiveness of corrective feedback (CF) in second language (L2) classrooms depends on various factors, such as different classroom contexts (e.g. ESL vs. EFL), students' proficiency levels, target structures, language aptitude, and students' attitude toward error correction. Often, these variables stem partly from L2 students' prior English learning experiences in their respective home countries, but almost no studies have connected these experiences to perceptions of CF. To fill this gap, the present study surveys the environments in which a group of sixty advanced-level adult ESL students studied English before coming to the United States, and considers how differences among classroom cultures-including how or whether oral CF and error correction were offered-influence these students' attitudes toward oral CF in the United States. Though Lyster and Saito (2010) found no significant contextual influences on the effects of CF in ESL or EFL 
institutional settings, each classroom offers unique learning processes, purposes, and circumstances. Thus, identifying and measuring contextual influence requires paying more concerted attention to how ESL students from different classroom cultures view and respond to teachers' oral CF. The present study is the first to articulate these connections, to help clarify how previous English learning influences L2 students' perceptions of their teachers' oral CF.

\section{LITERATURE REVIEW}

\section{Working Definitions of Academic Culture}

Academic culture is an especially relevant variable in the present study, both as a pedagogical context for corrective feedback and as a set of broader assumptions about language learning within the context of this study. Flowerdew and Miller (1995) offer a useful working definition of academic culture:

Academic culture refers to those features of the lecture situation which require an understanding of the particular academic values, roles, assumptions, attitudes, patterns of behaviors, and so on. Academic culture may be identified at various levels: at the level of a group of countries (e.g., Western countries); at the level of an individual country; at the level of a group of institutions within a given country; at the level of the individual institution within a given country. At any of these levels, a given academic culture is likely to be imbued with the values and practices of the ethnic culture within which it is situated (Flowerdew, 1986), and it may be difficult, in analyzing a given instance of behavior in an academic context, to ascribe such behavior to ethnic or academic influence (p. 362).

The participants in this study are adult ESL students, mainly from China, Korea, Japan, and Taiwan. These students had already studied English as a foreign language for many years in their respective home countries. In their interviews, several participants mentioned that public English secondary education in East Asian countries emphasizes reading and traditional grammar translation approaches based on rote-learning and memorization. Cain's (2012) description supports this anecdotal evidence: "in many East Asian classrooms, the traditional curriculum emphasizes listening, writing, reading, and memorization. Talking is simply not a focus, and is even discouraged” (p. 184). According to Hu (2003), this disparity creates a group of learners "who are able to achieve high scores on discretepoint grammar tests yet unable to communicate fluently and accurately in communicative contexts" common to American universities (as cited in 
Yang \& Lyster, 2010, p. 236).

By contrast, college classrooms in the United States often include and reward student discussion. American ESL classes typically make talking in English a priority. Similarly, American teachers tend to be less authoritarian and more approachable than their counterparts in Asian universities, and consider it normal to give direct personal feedback to individual students. Given these differences, Millar and Endo (2004) argue that ESL students need "some time to become comfortable in that type of environment" because so many American schools highlight "studentcentered learning, allowing students to do much of the speaking” (p. 789). Additionally, Millar and Endo (2004) emphasize that ESL teachers should "provide structure in the form of clear directions and...communicate with students individually" (p. 789). Because corrective feedback is engrained in many American classroom cultures, especially in L2 contexts, clarifying and demystifying those cultural expectations can help ESL learners acculturate to American universities. Indeed, Fowler-Frey (1998) argues that "instructors must endeavor to make the interaction between culture and learning in their classrooms explicit so that adult second language learners can participate fully in the learning of the second language in the classroom context” (p. 31). This participation is especially valuable for ESL students who go on to full-time academic study in American universities.

Given these contrasting attitudes toward talking in the classroom and toward corrective feedback, the present study proposes that error correction patterns in international students' past EFL classes may play a significant factor in how they perceive and respond to their teachers' oral CF. Simply put, students who are raised in American academic cultures may come to expect oral CF as a normal part of classroom conduct, especially in language classrooms. However, many otherwise experienced EFL learners have had little or no exposure to CF when they come to the United States, so they may process and respond to it very differently than their American peers. For this reason, much of this study's qualitative analysis examines differences in academic cultures, and their potential impact on student perceptions of and responses to American ESL teachers' oral CF.

\section{Oral Corrective Feedback in EFL vs. ESL Settings}

Lyster and Mori (2006) and Sheen (2004) indicate that "the occurrence and uptake of CF were very different across research or instruction setting, but experimental studies have not singled out research setting as an independent variable" (as cited in Li, 2010, p. 315). Given the differences between ESL and EFL learning processes, purposes, and circumstances, the effectiveness of oral CF might differ as well. This section will juxtapose ESL and EFL settings, and review three studies ( $\mathrm{Li}, 2010$; Lyster \& Saito, 2010; Yang \& Lyster, 2010) that explore some of their 
differences.

First, some working definitions are necessary. English as a Second Language (ESL) classes take place in a country where English is already the main or official language, most often the United States, Canada, the U.K., or Australia. Adult ESL speakers live or are planning to live in a country where their native languages are not used for education, business, and other activities, so they are under pressure to pick up "survival” language skills. Beyond the need for "survival English," many of these ESL students will continue their education in American community colleges, colleges, or universities, and thus need instruction on how to write academic research papers or give presentations in English. English as a Foreign Language (EFL) instructors, by contrast, teach English in countries where English is not a majority language. Current hot spots for EFL include South Korea, Japan, Taiwan, China, and Thailand. Students study English in their own countries as part of academic requirements in their school systems, or as preparation for travel or study in an English-speaking country. Many EFL students have years of grammar and vocabulary study, but they often lack practical skills in listening, speaking, and writing in English.

Lyster and Saito (2010) argue that there were no significant contextual influences on the effects of CF in ESL vs. EFL institutional settings, according to their quantitative meta-analysis study. However, Yang and Lyster's (2010) study shows that ESL and EFL learning situations may prompt different learning outcomes. Similarly, Li's (2010) meta-analysis of CF's efficacy in second language acquisition (SLA) indicates that "the mean effect size associated with the studies conducted in Foreign Language (FL) contexts was significantly larger than that associated with studies conducted in Second Language (SL) contexts, indicating that CF was more effective in FL contexts than in SL contexts" (p. 338). This finding corroborates those by Loewen et al. (2009). The participants in the FL settings, they find, have a more positive attitude toward teachers' error correction than the participants in the SL settings. Specifically, Loewen et al. (2009) argue that SL learners were "more enthusiastic about improving their oral communication skills," while FL learners gave "more priority to grammar instruction and error correction" (as cited in Li, 2010, p. 344).

Because many L2 learners transition from EFL to ESL settings when they study abroad, these contextual differences may create a variety of problems, especially as learners try to improve their spoken English proficiency. Specifically, the present study examines how differences between EFL and ESL academic culture, and between EFL and ESL approaches to oral English, might affect students' reactions to oral CF in ESL settings. To allow participants to articulate their attitudes toward CF and describe their previous English learning experiences, the present study uses mainly qualitative methods to draw out students' stories and 
characterize their approaches to CF in American ESL classrooms. This data might help ESL professionals customize their CF techniques and strategies in order to create a classroom environment suitable for enhancing L2 learners' oral production and proficiency. To that end, this study explores a single research question: How does students' prior English learning affect their perceptions of and responses to American ESL teachers' oral CF?

\section{RESEARCH METHOD}

This study uses a mixed method design with a combination of quantitative and qualitative data. More specifically, it uses a dominant-less dominant design: QUAN/qual sequential (Creswell, 1995). This design is "characterized by the collection and analysis of quantitative data followed by the collection and analysis of qualitative data. The priority typically is given to the quantitative data, and the two methods are integrated during the interpretation phase of the study" (Creswell, 2003, p. 215). Scholars disagree not only about the level of method in quantitative and qualitative methods, but also whether combining them is even workable (Denzin, 2008). However, using mixed methods in this way is not about convergence but rather crystallization. As Lather (2006) puts it, "the ability to situate oneself methodologically in the face of an imposed 'new orthodoxy' (Hodkinson, 2004) is not about paradigm competition but, much more profoundly, about a move away from a narrow scientism and toward an expanded notion of scientificity more capable of sustaining the social sciences" (p.47). In this case, for instance, using mixed methods allowed the researcher both to evaluate the worth of the data and draw out enough data to increase the credibility of the findings, by analyzing the data from multifaceted angles.

Similarly, by substituting inference transferability for validity, Tashakkori and Teddie (2002) demonstrate the fundamental principle of mixed or networked hybrid methodologies: "Methods should be mixed in a way that has complementary strengths and non-overlapping weaknesses" (p. 299, as cited in Demerath, 2006, p. 107). The primary benefit of this sort of design is that it "can provide stronger inferences-an important consideration for those working in a public field such as education" (Donmoyer, 2001, as cited in Demerath, 2006, pp. 107-8). More broadly, combining quantitative and qualitative research methods contributes greatly to bringing about more abundant data resources. Howe (2004) argues that qualitative methods may play a central role in helping strengthen inferences about causal relationships regarding why or how something is happening. Specifically, qualitative methods help researchers recognize the black box, 'gappy' understanding of the causal relationship. Therefore, in order to complement what quantitative research does not provide or show, a mix of quantitative and qualitative approaches is certainly required in the present 
study.

\section{Participants}

The study's participants, sixty advanced-level ESL adult students, were all completing their PhDs at a large Midwestern university, and were all training to be teaching assistants (TAs). In this role, all sixty would be expected to teach courses in their respective fields to college-level students. They were all enrolled in the university's intensive oral English program from March through June 2012, and were from a variety of countries: 36 were Chinese, 10 Korean, four Indian, two Japanese, two Taiwanese, two Thai, one Mexican, one Iranian, one Venezuelan, and one was from Hong Kong.

Before the program began, all the students were asked to take an institutional version of the Test of Spoken English (TSE), which measures the ability of nonnative English speakers to communicate effectively. A score of 230 on this test is required to gain TA certification, and the students in the present study all scored between 190 and 220. This means that they exhibited stronger English skills than their colleagues in the university's standard ESL program, but did not qualify for teaching certification. To gain that certification, each student had to achieve near-native levels of fluency in spoken English. Specifically, each one had to pass a mock teaching testa 10-minute lecture to a real audience-to demonstrate his or her oral English proficiency.

Forty of the sixty students participated in follow-up interviews. Because more than enough students showed enthusiastic interest in the interview, the researcher chose a representative sample based on the students' survey responses. Of the interviewed participants, 22 were Chinese, eight Korean, three Indian, two Japanese, two Taiwanese, one Thai, one Venezuelan, and one was from Hong Kong. The students' academic fields were somewhat diverse, though heavily weighted towards STEM (Science, Technology, Engineering, and Math) fields.

\section{Setting}

This study was conducted in a university-affiliated oral English training program hosted by a large university in the central United States. This program targets international teaching assistants (ITAs) whose native language is not English, to help improve the ITAs' ability to teach college courses in American English. The program has four sequenced courses, referred to here as Level 1, Level 2, Level 3, and Level 4. Each student takes a placement test upon admission to the university, and completes a teaching performance test at the end of the Level 3 course. This study collected data from Level 3 students, because the students there are relatively advanced and because they have been exposed to enough CF to recognize and discuss 
its effects on their English development. Indeed, the observed Level 3 classes featured frequent immediate oral $\mathrm{CF}$, and according to program documentation, instructors are trained to stop and correct students whenever there's a problem with the students' communication. Students are then asked to repeat their utterances, making the suggested corrections. Because most of the students at the host university are native American English speakers from the Midwest region, the program prioritizes making ITAs' speech comprehensible to that audience, which often requires accent reduction and favors certain dialects of American English.

\section{Instruments}

The data were collected by means of classroom observations, a survey questionnaire, and in-depth follow-up interviews with a majority of the survey respondents. The survey was given after a month of instruction and $\mathrm{CF}$, and included questions examining the students' EFL backgrounds, to assist in interview planning and data analysis.

The interview questions engaged both the students' quantitative and qualitative survey responses. Interview data played a significant role in clarifying the interviewed subjects' prior EFL experiences, and provided rich and abundant resources to organize and analyze the qualitative survey data. At the end of the survey, participants were asked if they were interested in follow-up interviews, and forty interviewees were selected from the pool of interested students. All forty interviewed students were asked the set of fourteen interview questions, and each interview lasted 60-70 minutes. The interviews were conducted in English, in a quiet and empty classroom, and each interview was recorded and immediately transcribed.

\section{Data Analysis}

Descriptive statistics were used to examine the relationship between students' prior English learning experiences and their perceptions of their American teachers' oral CF. Specifically, students' responses to the statements regarding their EFL learning environments, as well as the statements regarding their responses to their American ESL teachers' oral $\mathrm{CF}$, were summarized. Based on the students' interview responses, the qualitative interview data were analyzed and coded in accordance with three themes: students' previous training in oral English, EFL pedagogy and curriculum, and student-teacher interaction. To ensure more accurate and fine-tuned qualitative data analysis, the codes of the students' responses were re-examined and revised three times by two qualitative data analysts with expertise in ESL education. In order to establish credibility, member checks by both analysts were utilized to corroborate face validity and to confirm the transcripts' accuracy.

There will be differences of opinion regarding the validity of students' views of CF and its effects. Some would argue that post hoc and 
decontextualized views are not valid, and must instead be embedded within a specific situation.

\section{RESULTS}

\section{Students' EFL Learning Experiences and their Perceptions of CF}

\section{Quantitative Results}

The research question examines how students' prior EFL classes in their own countries influence their perceptions of and attitudes toward their American teachers' oral CF. Figure 1 shows the students' mean ratings on each of the eight declarative items.

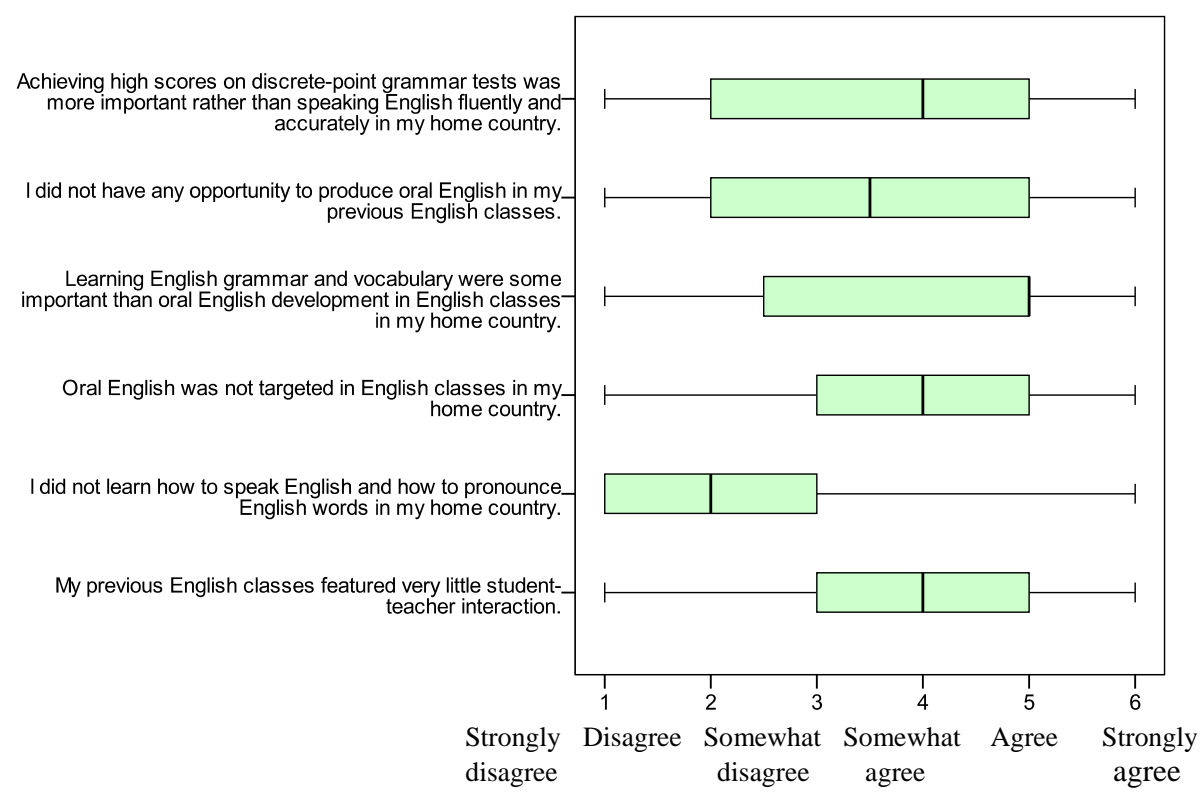

Figure 1. Quantitative ratings of students' EFL learning environments

Figure 2 summarizes the students' attitudes toward their American teachers' oral CF. As shown in Figure 2, the majority of students preferred the US classrooms, where they could get plentiful oral CF from their teachers. A few students, however, preferred the English learning environments in their home countries, where they received no CF.

While the quantitative results provided general accounts of the respondents' EFL classrooms and their feelings about corrective feedback, they did not produce sufficiently detailed information to answer the research question effectively. Accordingly, the qualitative data, especially the interview data, clarified the participants' experiences in terms of lesson content and ESL vs. EFL oral English pedagogy, and suggested how 
differences in classroom cultures influenced the participants' perceptions of and attitudes toward American ESL teachers' oral CF.

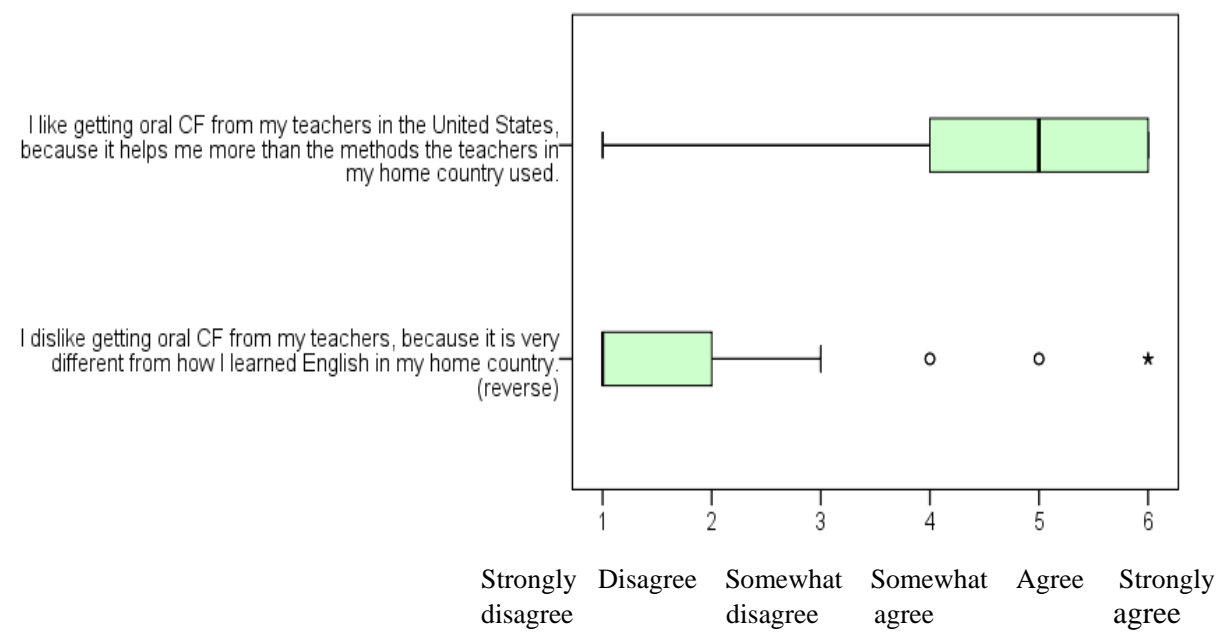

Figure 2. Students’ Responses to American Teachers’ Oral CF Qualitative Results

Among the forty interview participants, several students transferred to the study's host university from universities in their own countries. For this reason, in order to be consistent with their accounts of the shared common classroom environments and cultures, the interviews focused more on their high school (secondary) English education than on its college counterpart, though students gave examples from classes on both levels.

\section{Students' Previous Training in Oral English}

Out of forty interview participants, twenty-two students learned how to pronounce some English words in their own country, while eighteen students did not. However, these lessons did not emphasize real-world conversations: instead, the students just mimicked their teachers' pronunciation and repeated textbook passages that their teachers read aloud. Furthermore, their teachers' pronunciation instruction was vocabulary-level, and they did not teach students how to use intonation, stress, and accent to enhance communication. The following representative interview transcriptions show what the interview participants' oral English classes were like. In the citations, "P" stands for "Participant."

We had a textbook; then my English teachers [in India] took a lesson. They will describe the-usually the English lessons are based on some stories, or they will talk about some leaders' qualities, and so on. 
So those lessons are helpful to me to learn the vocabulary, grammar. But it doesn't take care of my oral English, how to communicate to a large audience, how to make an effective speech and so on. So it's purely based on vocabulary and grammar (P30's personal interview, June 8, 2012).

In Korea, my English teachers didn't show or teach how to pronounce exactly, and they did not teach the intonation, accents, and rhythm for oral English. I think they have avoided pronouncing it, because they didn't have any confidence. That's why they just focus on grammar or vocabulary or reading (P1's personal interview, May 29, 2012).

Along the same lines, twenty-seven students did not have any opportunities to practice their oral English in their previous high school English classes, whereas thirteen students did. Even in college, opportunities to practice their oral English were still insufficient; only fifteen students were given the opportunities to practice their oral English, while twenty-five students were not:

I think because I didn't have so many opportunities to practice in China, I felt pathetic. Like, I had been studying English for maybe 10 years. And until now, I couldn't learn to speak English right. I think it's really pathetic. [...] When our previous English teachers taught English in the classes, the teacher pronounced a particular sound and said follow that, repeat that for a couple of times; then, it's done. Then after class, it's done. We didn't speak anymore. In college, it's still not that much. Because after class, we didn't speak unless we had foreign friends (P14's personal interview, May 25, 2012).

As I said, I didn't have a chance to produce or practice my oral English. So when I learned English in Korea, I didn't know where I made a mistake. Whenever I read the perfect sentences, I could understand them, so I believed that I could make those kinds of sentences. But actually, even though I know what the correct form is, and even though I can understand the written English, it's totally different from what I am saying (P23's personal interview, June 13, 2012).

\section{EFL Pedagogy and Curriculum}

All forty students reported similar procedures in their EFL classes: they read their textbooks, memorized a certain amount of vocabulary, and analyzed English grammatical structure. Accordingly, the language skills emphasized in their previous English classes followed this hierarchy: 
grammar, reading, vocabulary, writing, and listening skills. All forty students asserted that grammar, reading, and vocabulary were the main focus of their EFL classes, and thirty-two students each cited writing and listening skills. Since the college entrance examinations differ by country, the highlighted skills depended on what the exam tested.

Unfortunately, speaking skills were not included in the students' college entrance examinations, and what's worse, oral English for communication was hardly ever taught in their previous classes. That is why speaking English gave all forty students the most difficulty when they came to the United States. All the interview participants mentioned that they were afraid of speaking English: they did not have any confidence in their oral English and they were not able to communicate with Americans in English, so they avoided speaking English with others in the USA.

I didn't know how to express my ideas even though I just read the article, I didn't know how to express my feeling, and I didn't know how to output what I thought. When I see some word, I know its meaning, but when I want to say it, I can't recall the word (P5's personal interview, May 23, 2012).

I think it's the way we speak English, it's the way-so it's the difference between the way you speak English in India and the way we speak in the United States. The two are just different. So before you get the hang of it, you are going to have that difference. And I think even if you observe some people from Asia, some adults (from the continent), usually other than when they're speaking to an American or a native citizen, or a native speaker, when they're speaking English to a person from their same country, you will find a difference in that also (P28's personal interview, May 29, 2012).

More specifically, all forty students agreed that their speaking problems came from their pronunciation. Their incorrect pronunciations prevented them from communicating with Americans in natural settings, and caused miscommunication and confusion in their English conversations. The next set of transcriptions probes how the students' different pronunciation affects their oral English communication:

The difficulty was that sometimes they couldn't understand what I said right away. That was a bit depressing. I think it's because of intonation and pronunciation. Like if I asked a question, then I emphasized the wrong word. But when I came here, one of my classmates who is American kept asking me, " 
Pronunciation is a lot. Because I worked with my American teacher, I found a lot of differences. Because in India, we will say "adwantage"; here they will say "advantage". And the other stuff, umm... "FY-nance", "fih-NANCE". These are all differences between British English and American. Then we will call it a "meCAN-ism"; here they will call it a "MECK-a-nism". Then we will call it a "CON-figuration"; here they will call it a "con-FIG-u-RAYtion". So these are all different ways. Most problems are related to pronunciation, intonation, and rhythm. Rhythm and intonation are entirely different here (P30's personal interview, June 8, 2012).

Thirty-three students also identified their lack of opportunity to practice their oral English in their own country as an important aspect of their oral English deficiency. Since their previous English classes were extremely focused on grammar, reading, and vocabulary, and ultimately on higher test scores, they did not have any chances to practice their speaking. Their EFL classes mainly involved students memorizing a lot of English grammar, learning vocabulary, and doing sentence-level translation to enhance their reading comprehension skills. In other words, the students were given a large amount of input, rather than outputting what they had learned. In fact, nine students pointed out they were less confident in speaking English because they mainly learned English grammar and reading in their previous English classes.

In addition to speaking skills, eleven students indicated that the next largest difficulty came from their limited vocabulary, and seven students identified listening skills as a problematic language skill. This is because the textbooks and materials used in their previous English classes were quite out-of-date, and they did not include contemporary examples to help the students master practical and colloquial oral English. In addition, the recordings for the textbooks did not follow American's actual conversational speaking speed, and the recorded conversations used fairly formal expressions not used in real-life situations. This limitation, one student estimated, meant that $40 \%$ of the actual oral English [she] encountered "is totally different [from the textbook]. There were different intonations, different accents, different speaking speeds” (P10's personal interview, May 24, 2012).

\section{Student-Teacher Interaction}

Regardless of course content, the participants' EFL classes were predominantly teacher-centered, and there was little interaction between students and teachers. One student noted that his EFL teachers "just taught you how to use the grammar," and while they would sometimes use questions to test students' comprehension, the students were expected to 
keep quiet (P34's personal interview, June 6, 2012). Seven other students highlighted similar scenarios, pointing out that student-teacher interactions represented a central cultural difference between ESL and EFL classrooms. These differences were especially poignant for Asian students:

I think most of the classes are teacher-centered in China. Because one thing is that we have so many students. So the teacher will control the whole classroom. And also, it may be a culture thing, because maybe in Chinese traditions, we need to respect the teachers. I think in China it's really rude to interrupt the teachers during the classes. So we cannot break the habit of listening to the teachers (P15's personal interview, May 29, 2012).

I think Asian students are a little shy. I didn't like to express myself. From my 20 years' experience, I didn't feel like interacting with professors, and I had a kind of fear of the professors. So sometimes I felt so nervous, and I didn't dare to talk to them. Even though, like for American students, I think they feel more comfortable. Sometimes they made jokes with their professors, but for me, I didn't know how to do it! I can't! (P23’s Personal interview, June 13, 2012).

Along similar lines, eight students pointed out that their American classes often featured one-on-one tutorials with their teachers, a feature which their previous English classes did not have:

In China, English teachers just teach you something. "Okay, this is what you need to learn." But here, all teachers are dependent on individuals. Like, personal tutorial - this is a very important thing. Well, I must say it's impossible in China, because you know, we have a large number of students, around 50 or 60 students in one class. Also, American teachers are more willing to know each student's personal perspective, and willing, and they can establish more individual way to improve our English. But in China, they can just give you criteria. "Okay! You just follow this, and learn these words, that's it" (P31's personal interview, June 11, 2012).

Because corrective feedback requires personal, targeted interactions between a teacher and a student, the participants also discussed their attitudes toward oral CF in terms of these interactions. As mentioned above, most of the participants preferred getting CF to not getting it, and they offered two main reasons for this preference. Thirty-nine students maintained that American teachers corrected their oral English and incorrect 
pronunciation, while their EFL teachers did not correct their incorrect pronunciation, and in fact offered very little corrective feedback on their oral English. Among these 39, eighteen students highlighted that their teachers' English in their own country was not perfect, whereas American teachers speak perfect English, as they are all native speakers.

By the same token, thirty-seven students contended that American teachers not only know how to teach oral English, but unlike their EFL counterparts, they also showed students how to pronounce vowels and consonants in great detail, including how to shape the mouth and where the tongue should be located to make Americanized sounds. Several students specifically praised their additional expertise:

As I told you, my previous English teachers didn't provide individual feedback like this. But, here my American teacher knows what the errors for Chinese are, what are the errors for Thais, for other countries in Asia, so she can-she knows, even, like, "You pronounce L like this, but you should pronounce L like this." They know, even, how we pronounce these words. So I think-I'm not sure if the teachers who taught in Thailand know this, know our weaknesses, our errors (P12's personal interview, June 1, 2012).

We do get oral corrective feedback, but that oral corrective feedback is mapped in the way Indian English has been spoken. It's like, funny, because they're Indian English speakers, and they correct in an Indian speaking way. It won't be exactly the same way that Americans are pronouncing it, but people in America might understand it. They can change my English to understandable English, acceptable English, but it's not good English, it's not real American English. It's not American English. They just correct in an Indian English speaking way (P28's personal interview, May 29, 2012).

The study accomplishes this by paying attention to what went on in participants' English classes, how their prior teachers' oral English pedagogy compared to their U.S. teachers' pedagogy, and how studentteacher interaction contextualized and affected CF preferences.

\section{DISCUSSION}

To generate consistent and coherent scholarly discussions about CF effectiveness in the ESL classroom, teachers and researchers need to cope with adult ESL students' expectations for CF and student-teacher interaction. Even though several scholars (e.g. Ellis et al., 2006; Ellis, 2007; 
Yang \& Lyster, 2010) have recognized the importance of students' prior English learning experiences in their respective home countries in terms of specific pedagogical tasks, no previous studies examined the relationship between these students' EFL feedback patterns and their views of oral CF in ESL contexts.

Other than four students (those from India and Hong Kong) who initially learned English as a second language (ESL), the rest of the participants studied in an English as a foreign language (EFL) context. The key difference between the ESL and EFL students was whether they had sufficient opportunities to practice their oral English in their own English classes. This brought about a big difference in speaking English confidently and fluently. For instance, because the Indian students in this study were used to English as a primary language of education, none of them had any problems listening to American professors' lectures, writing their essays, and freely contributing their opinions to classroom discussion. On the other hand, English was not used as a lingua franca in any of the other students' previous classes, so they did not have enough opportunities to practice their oral English. Based on the qualitative results from the interviews, twentyseven students did not have any opportunities to practice their oral English in their previous high school English classes, whereas thirteen students did. Even in college, opportunities to practice their oral English were still insufficient: only fifteen students were given the opportunities to practice their oral English, while twenty-five students were not.

In addition, these students' previous English teachers almost never taught them tongue-twisters, or how to use their facial muscles to pronounce English correctly. Although twenty-two out of forty interview participants learned how to pronounce some English words in their own countries, their oral education was focused on mimicking their teachers' pronunciation and repeating textbook passages that their teachers read aloud. Their teachers' pronunciation instruction was also vocabulary-level, meaning the students were not taught how to use intonation, stress, and accent to communicate in English. This fact offers more substantial evidence for the drastic differences between oral English education within and outside of the US. More seriously, oral English for communication was hardly ever taught in participants' previous English classes since speaking skills were not included in their college entrance examinations. Accordingly, speaking English gave all forty students considerable difficulty when they came to the United States, and they were afraid of speaking English. These findings support Derwing and Munro’s (2013) recommendation that "ESL programs should put a greater focus on oral language skills in the beginner stages of language acquisition, particularly because some L2 students do not access much oral language outside the classroom” (pp. 180-181).

Obviously, these particular students are not the only ones to suffer 
from this imbalance: a similar problem emerged among the Canadian French immersion students in Swain's (1985) study. Even though the Canadian students were given considerable comprehensible input in the target language (French) for almost seven years, their productive competence in the target language-especially in terms of grammatical performance-was not equal to that of native speakers. According to Swain's (1985, 1993, 1995) argument, this was because the students' comprehensible output, not their comprehensible input, was limited. Further, she demonstrated that these students were not pushed sufficiently in their output. In particular, Swain's personal communication with an immersion student, conducted in November 1980, confirms that one function of output is to offer students "the opportunity for meaningful use of one's linguistics resources": "I understand everything anyone says to me, and I can hear in my head how I should sound when I talk, but it never comes out that way.” For this reason, "producing the target language may be the trigger that forces the learner to pay attention to the means of expression needed in order to successfully convey his or her own intended meaning” (Swain, 1985, pp.248-249).

The present study supports Swain's (1985, 1993, 1995) conclusion: having sufficient opportunities to practice and output the target language in ESL classroom contexts plays a significant role in improving students' productive English competence. Ortega (2009) further contends that these opportunities should push learners beyond their current L2 competence, particularly in cases where the learners' erroneous interlanguage has been stabilized over the course of many years. The students who participated in the present study lacked these opportunities because their previous English classrooms were focused so much on teacher-centered education, which limited students' opportunities to interact with their teachers and peers to practice their oral English. However, since coming to the US and to a very different set of student-centered classroom cultures, which required more interactions with their American teachers, these students' English learning has been dramatically affected.

\section{LIMITATIONS AND FUTURE RESEARCH}

The present study brackets the political dimensions of the standards for "correct" English pronunciation. Any standard for pronunciation implies certain political views about who should speak English and how, and what is "normal” or "proper" English (Luk \& Lin, 2006). These political debates, while outside the purview of this study, are especially important to understanding ESL and EFL education in a multilingual and multiethnic educational environment like the United States. However, within the context of the study's host program, the importance of pronunciation is from a practical perspective: the students need to improve their oral English 
proficiency both in order to teach college-level students in Midwestern US classroom contexts, and to ensure their future students comprehend and understand their lectures. On a practical level, those students are most used to hearing and speaking Midwestern US English. For this reason, throughout the semester the students were given plentiful opportunities to refine their pronunciation to a level at which they could communicate effectively in the American university classroom.

Additionally, one current question in CF scholarship is the comparative effects of CF in ESL and EFL institutional settings: Lyster and Saito (2010) argued there were no significant contextual differences between the two settings, based on their quantitative study using meta-analysis. Although the present study did not uncover any significant quantitative results to address this issue, a portion of the qualitative data is relevant here. Specifically, interviews with three Indian participants demonstrated the value of previous English studies in contexts where English is the primary language of education. Unlike their fellow study participants, who had studied in teacher-centered EFL contexts described earlier in this study, the Indian students had many opportunities to practice and output their oral English during their English classes in India. This made a big difference in their ability to speak English confidently and fluently, and improved their overall oral English proficiency. Future research should examine EFL vs. ESL backgrounds more directly, to explore the association between oral CF and different institutional contexts, which might affect CF types and strategies for L2 learners' oral production.

\section{REFERENCES}

Cain, S. (2012). Soft power: Asian-Americans and the extroverted ideal. In S. Cain (Ed.), Quiet: the power of introverts in a world that can't stop talking, (pp. 181-202). New York: Crown Publishers.

Creswell, J. W. (1995). Research design: Qualitative and quantitative approaches. Thousand Oaks, CA: Sage Publications.

Creswell, J. W. (2003). Research design: Qualitative, quantitative, and mixed methods approaches $\left(2^{\text {nd }} E d\right.$.). Thousand Oaks, CA: Sage Publications.

Demerath, P. (2006). The science of context: Modes of response for qualitative researchers in education. Journal of Qualitative Research in Education, 19, $97-113$.

Denzin, N. (2008). The new paradigm dialogs and qualitative inquiry. Qualitative Studies in Education, 21, 315-325.

Derwing, T. M., \& Munro, M. J. (2013). The development of L2 oral language skills in two

L1 groups: A 7-year study. Language Learning, 63(2), 163-185.

Ellis, R. (2007). The differential effects of corrective feedback on two grammatical structures. In a Mackey (Ed.), Conversational interaction in second language acquisition: A collection of empirical studies (pp. 407-452). Oxford: Oxford 
University Press.

Ellis, R., Loewen, S., \& Erlam, R. (2006). Implicit and explicit corrective feedback and the acquisition of L2 grammar. Studies in Second Language Acquisition, 28, 339-368.

Flowerdew, J., \& Miller. L. (1995). On the notion of culture in L2 lectures. TESOL Quarterly, 29, 345-373.

Fowler-Frey, J. M. (1998). Issues of culture in the adult English as a second language classroom. PAACE Journal of Lifelong Learning, 7, 29-42.

Hodkinson, P. (2004). Research as a form of work: Expertise, community and methodological objectivity. British Educational research Journal, 30, 9-26.

Howe, K. R. (2004). A critique of experimentalism. Qualitative Inquiry, 10, 42-61.

Hu, G. (2003). English language teaching in China: Regional differences and contributing factors. Journal of Multilingual and Multicultural Development, 24, 290-318.

Kim, J. H. (2004). Issues of corrective feedback in second language acquisition. Teachers College, Columbia University Working papers in TESOL \& Applied Linguistics, 4(2), 1-24.

Lather, P. (2006). Paradigm proliferation as a good think to think with: Teaching researcher in education as a wild profusion. International Journal of Qualitative Studies in Education, 19, 35-57.

Li, S. (2010). The effectiveness of corrective feedback in SLA: A meta-analysis. Language Learning, 60, 309-365.

Loewen, S., Li, S., Fei, F., Thompson, A., Nakatsukasa, K., Ahn, S., \& Chen, X. (2009). L2 learners' beliefs about grammar instruction and error correction. The Modern Language Journal, 93, 91-104.

Luk, J., \& Lin, A. (2006). Uncovering the sociopolitical situatedness of accents in the World Englishes paradigm. In R. Hughes (Ed.), Spoken English, TESOL and applied linguistics: Challenges for theory and practice (pp. 3-22). Palgrave Macmillan.

Lyster, R., \& Mori, H. (2006). Interactional feedback and instructional counterbalance. Studies in Second Language Acquisition, 28, 269-300.

Lyster, R., \& Saito, K. (2010). Oral feedback in classroom SLA: A meta-analysis. Studies in Second Language Acquisition, 32, 265-302.

Millar P. C., \& Endo, H. (2004). Understanding and meeting the needs of ESL students. The Phi Delta Kappan, 85(10), 786-791.

Ortega, L. (2009). The linguistic environment. In L. Ortega (Ed.), Understanding second language acquisition (pp. 55-81). London: Hodder Arnold.

Rezaei, S., Mozaffari, F. (2011). Corrective feedback in SLA: Classroom practice and future directions. International Journal of English Linguistics, 1(1), 2129.

Russell, V. (2009). Corrective feedback, over a decade of research since Lyster and Ranta (1997): Where do we stand today? Electronic Journal of Foreign Language Teacher, 6(1), 21-31.

Sheen, Y. (2004). Corrective feedback and learner uptake in communicative classrooms across instructional settings. Language Teaching Research, 8, 263300.

Sheen, Y. (2010). The role of oral and written corrective feedback in SLA. Studies in Second Language Acquisition, 32, 169-179. 
Swain, M. (1985). Communicative competence; some roles of comprehensive input and output in its development. In S. Gass \& C. Madden (Eds.), Input in second language acquisition (pp. 235-53). Cambridge, MA: Newbury House.

Swain, M. (1993). The output hypothesis: Just speaking and writing aren't enough. Canadian Modern Language Review, 50, 158-164.

Swain, M. (1995). Three functions of output in second language learning. In G. Cook \& B. Seidlhoffer (Eds.), Principles \& practice in applied linguistics: Studies in honor of H. G. Widdowson (pp. 125-44). Oxford: Oxford University Press.

Yang, Y., \& Lyster, R. (2010). Effects of form-focused practice and feedback on Chinese EFL learners' acquisition of regular and irregular past tense forms. Studies in Second Language Acquisition, 32, 235-263.

EUN JEONG (ESTHER) LEE, Ph.D., is the Director of the Intensive English Language Program and an Assistant Professor of English and Foreign Languages at Claflin University. Her specific research interests include corrective feedback, the affective elements of L2 pedagogy, emotion and learning, informal English conversations, ESL learning patterns, curriculum development, and ESL program management. Email: eulee@claflin.edu. 